\title{
Review of Sustainability in Self-compacting Concrete: the Use of Waste and Mineral Additives as Supplementary Cementitious Materials and Aggregates
}

\author{
Ayobami A. Busari*, Joseph O. Akinmusuru and Bamidele I. Dahunsi \\ Department of Civil Engineering, Covenant University, Canaanland, Ota, Ogun State, Nigeria
}

Received March 2, 2017; accepted September 12, 2017

\begin{abstract}
Concrete is one of the most commonly used construction materials, but there is a need to develop a new and sustainable technology to make it more affordable. With the advancement in technology, concrete is no longer seen as a composite of three elements (binder, aggregate, and water). The distinctive workability properties of SCC make it unique in the concrete industry. This review has assessed the materials, strength and rheological properties of agricultural waste, industrial waste and mineral additives in SCC production. The effect of the utilization of these additives and replacements on structural, mechanical and rheological properties of SCC has been studied. This review has revealed that the use of both industrial and agricultural waste enhances the strength properties of SCC. Additionally, the use of agricultural waste improves the rheological properties of fresh concrete. The utilization of expansive materials should be discouraged in SCC production. This review has revealed that SCC developments ensure a good balance between deformability and stability. It is therefore recommended that SCC is utilized in pavement construction, particularly when high axle load is expected.
\end{abstract}

Keywords: Self-compacting concrete, mineral additives, agricultural waste, structural properties, rheology.

\section{Introduction}

\section{Origin of self-compacting concrete}

Self-compacting concrete (SCC) is an innovation and a breakthrough in the construction industry. It provides many new solutions to fresh and hardened properties of concrete. SCC is also referred to as self-consolidating concrete, self-leveling concrete, super-workable concrete, highly-flowable concrete and non-vibrating concrete [1]. The origin of SCC can be traced back to the 1980s, due to the shortage of skilled man power in concrete producing industries and construction sites in Japan. Mohite [2] avowed that the use of SCC was originally developed with the aim to solve the durability problem in structures that have got

\footnotetext{
* Corresponding author. E-mail address: ayobami.busari@ covenantuniversity.edu.ng
} 
congested reinforcement. The excellent user-friendly characteristics of SCC are of great attraction in the traditional construction industry. Ouchi [3] asserted that the problem of manpower in concrete production became a major topic of interest several years ago, due to the gradual reduction in skilled labour. As a result, there was a need for this special concrete and, hence, the development made by Okamura [4], precisely in 1986. Additionally, Naik et al. [5] traced the origin to the University of Tokyo, Japan, in collaboration with leading concrete contractors during the late 1980s.

\section{Definition and application of SCC}

By definition, SCC is a special type of high strength and high-performance concrete, used for construction purposes, that requires no mechanical vibration. It is flowable, as well as deformable without segregation $[1,6,7]$. It flows under its weight, and hence, it has revolutionized concrete placement [2]. Because of its strength and rheological properties, this unique concrete tends to offer several usages in the construction world. Furthermore, Patil et al. [8] have asserted that SCC has got an increased quality and reduced deterioration, since the vibrator trails and mechanical vibrating equipment, which frequently result in over consolidation of concrete works, are not used.

Aggarwal et al. [9] avowed that SCC is a quiet, cost effective, energy saving, and low carbon footprint concrete technology, due to the absence of vibrators. According to Ouchi and Hibino [10], SCC offers many advantages for the precast, prestressed concrete industry and cast-in place construction, such as low noise, less labour, faster construction, high strength, etc. According to [11], applications of SCC showed that it reduces construction costs, because the need for vibrators and manpower is reduced, and noise pollution is also greatly reduced, especially in urban and suburban construction sites.

SCC has been adopted in the building of bridges, tunnels, and other structures; the successful development of SCC guarantees a right balance between deformability and stability [12]; however, its application in pavement construction is not significant. Based on the uniqueness of this special concrete, there is a need to assess the effect of the use of sustainable materials in its design, methodology, and strength. The use of sustainable materials in the form of industrial and agricultural waste and minerals will reduce the waste in our environment, and give a better, greener and alternative use to these solid wastes.

\section{Materials and methodology used for achieving self-compatibility}

Concrete mix for self-compacting concrete differs from normal concrete, due to the volume of both coarse and fine aggregates necessary to ascertain its required flow and workability. According to [11], to achieve a workable SCC, the mix must be cohesive, with good rheological properties, hence, the water cement ratio and moisture content of the constituent ingredients should be adjusted. This is because the rheological and the cohesive properties of SCC differ from the conventional concrete. However, Aitcin [13] has stated that the major difference between self-compacting concrete and normal strength concrete is in the 
percentage of high-range water reducer (or super plasticizer); normal strength concrete rarely contain this, but all other basic ingredients are the same.

According to the research done by Khayat [14], a set of guidelines was suggested, which include, amidst others, the reduction of the coarse aggregate ratio, an increase in the paste volume and the use of viscosity modifying admixtures. It is a known fact that SCC design must cater for both stability and strength, which often are affected by the concrete mix characteristics. A good SCC mix should possess unique-homogeneity attributes, in order to ensure adequate structural performance and durability. To exhibit these characteristics and rheological properties, the use of super plasticizers is inevitable [5]. SCC is characterized by its special rheological properties: low yield stress, which ensures high flow ability, and adequate viscosity, which prevents aggregate segregation; this was based on excess paste theory, as proposed by Kennedy [15]. Based on this theory, to ensure good flow ability, there must be a sufficient amount of paste in mortar or concrete, which not only fills up the spaces between aggregate particles, but also coats the particles surface, to minimize the friction among them. This layer of paste that coats aggregate particles is called "excess paste layer".

The rheological properties and the thickness of this excess paste layer significantly contribute to the methodology adopted in the production of selfcompacting concrete, by improving the flow ability of the fresh concrete. The degree of inter-particle friction greatly influences the properties and thickness requirements of this excess paste layer.

Also, research by Okamura [4] has revealed that both fine and coarse aggregate should be fixed to achieve self-compatibility. Using the approach in mix design, the aggregates were fixed, and the water cement ratio and other admixtures were adjusted. The fine and coarse aggregates were fixed at 40 and 50 percent, respectively. Also, Aggarwal et al. [9] investigated the mix design procedure for self-compacting concrete, using different mix ratios. The water-binder ratio has varied, but with a special focus on workability and flow properties, which were found to be satisfactory using the L-box and V funnel apparatus.

There exist different guidelines for the design of SCC, although one of its major limitations is that there are no established mix designs yet. However, some mix design methods are peculiar to a few regions, such as Europe and Japan, and so on.

Aggarwal et al. [9] have used the Japanese method for the design of a SCC mix. This was achieved by using the volume batching approach, with a super plasticizers dosage of $0 \%$ to $0.76 \%$ and $3.8 \%$ for three trial mixes. The results have showed that, as the water powder increased from 1.180 to $1.215 \%$, the rheology of the SCC mix was found to be adequate. Using grade 43 of cement gave a strength value between $25 \mathrm{MPa}$ and $33 \mathrm{MPa}$, at maturity of 28 days. Correspondingly, Vengala et al. [16] made SCC to achieve a good workability by altering the paste composition, while the aggregate volume remained the same. This has confirmed the theory that flow ability is primarily a function of the paste matrix, as suggested by Kennedy [15]. Furthermore, Girish et al. [17] explained the results of the experimental work on the effect of powder content on self- 
compacting mixtures. The results have showed a positive relationship between flow properties and an increase in paste content. It can be established that different methods and approaches are available for SCC production.

\section{Sustainable admixtures used in SCC}

Sustainability in concreting deals with the use and reuse of materials, especially waste and mineral resources in concrete mix design. Despite the fact that one of the major SCC attributes is that it must possess high strength, the use of cementitious materials is higher than in conventional concrete, which invariably increases production and construction costs. The use of sustainable supplementary materials helps in reducing SCC production costs. Nonetheless, technology, to a very large extent, changes perception and, as such, concrete is no longer viewed as consisting of only binder, aggregate, and water. Improved technology has paved the way for the addition of other constituents, in order to meet up with consistency, rheology and strength, as demanded. In an effort to reduce production and construction costs sustainable materials have recently started to being used as additives. These sustainable additives include minerals, agricultural products, and industrial waste. Some of the mineral additives commonly utilized are fly ash, silica fume, slag, metakaolin, and so on. It is worthy to note that the use of these additives has improved the strength properties of the concrete, as opposed to only using pure Portland cement. Often, these supplementary materials are varied, either by volume or by weight, depending on the methodology adopted. Grdic et al. [18] carried out an experimental investigation using mineral additives, which included silica fume, hydraulic lime and a mixture of fly ash. The effect of these additives was investigated on the behaviour of self-compacting concrete in both fresh and hardened states. The results showed that the mix containing fly ash and hydraulic lime proved to be the best in both fresh and hardened states. The authors have also asserted that the use of water reducers or retarders and super plasticizers is important in the production of self-compacting concrete. Additionally, Guneyisi et al. [19] have worked on nano silica and fly ash content, which were varied and assessed on both rheological and fresh properties of self-compacting concrete. Naik et al. [6] assessed the structural properties of two classes of fly ash, using $15 \%$ and $25 \%$ by mass of class $\mathrm{F}$ and class $\mathrm{C}$, respectively. The main purpose of the research was to evaluate the time of setting, compressive strength, drying shrinkage, and abrasion resistance of the developed SCC. Also, Khaloo and Houseinian [20] assessed silica fume effect on SCC production, at both long and short term. The results have showed that the additive improved the strength properties of the produced SCC concrete. Ray and Chattopadhyay [21] varied the percentages of silica fume by weight, using $2 \%$ increment, and its effect on SCC was studied, which also showed an improved strength. Kamal et al. [22] considered polypropylene fibre in the production of SCC, by assessing its mechanical strength, which has indicated an improvement at the considered different ages. 


\section{Agricultural and industrial waste as sustainable supplementary materials in SCC production}

Agricultural waste has been explored as a supplementary material in the construction industry. Bagasse ash is an abundantly available combustion byproduct in the sugarcane industry, and its effect on SCC production was studied by Sua-iam and Makul [23]. Research by Sua-iam and Makul [24] has adopted the use of lignite coal fly ash (FA), as a replacement for Type I Portland cement (OPC), and a high volume of rice husk ash (RHA) was utilized as a replacement for fine aggregates. Tire Rubber Crumb (TRC) was used as a partial sand replacement $(5 \%, 10 \%$, and $15 \%)$ by Hesami et al. [25]. Ranjbar et al. [26] used industrial slag, and its effect was studied on the rheological properties, selfcompatibility and strength properties of self-compacting concrete. Sethy et al. [27] considered the presence of alunimo-silicate based fine aggregates in SCC production, using 2.5 to $7.5 \%$. Barluenga et al. [28] showed the risk of SCC cracking, due to dry shrinkage, using mineral admixtures. This was achieved by combining limestone fillers with several active mineral additions, such as metakaolin (MC), microsilica (MS) and nanosilica (NS). This has affected the micro structural hydration of the samples. Six concrete compositions with high range water reducing admixtures were designed using a fine water ratio of 0.36 throughout the investigation. The authors have concluded that, at early ages, limestone fillers accelerate the speed of hydration. Also, the temperature was found to be an important parameter for assessing cement hydration reaction.

Additionally, there was a research (Barluenga et al. [28]) about the effect of dosage and nature of some selected mineral admixtures on the ages of heat treated self-compacting concrete. The selected admixtures were granulated slag (GS), and crystallized slag (CS). These admixtures, according to the research, had an impact on the strength of fresh self-compacting concrete.

\section{Effect of using sustainable admixtures on the strength properties of self- compacting concrete}

According to [11], the strength properties of SCC in the hardened state are quite similar to high-performance concrete, of which SCC is a subset. Sadek et al. [29] assessed the utilization of mineral additives (solid waste) in the production of self-compacting concrete. Three types of solid waste were utilized: granite powder, marble powder and mixed powder. Using waste powders as admixtures affects the structural and durability properties of SCC, both in the fresh and hardened states.

Research on SCC with use of Palm Oil Fuel Ash (POFA) agricultural waste as a supplementary material was made by Ranjbar et al. [26]. The utilization of this agricultural waste has reduced SCC workability. Although the samples with a higher amount of POFA have revealed lower surface water absorption, the durability under acid attack was satisfactory, compared to the samples with a lower content of POFA. It was opined that the resistance of SCC against acid attack was due to the pozzolanic reaction of POFA conversion of calcium hydroxide $\mathrm{Ca}(\mathrm{OH})_{2}$ into the secondary $\mathrm{CeSeH}$ gel, leading to a denser concrete. The gained compressive strength showed, at a higher volume of POFA, $15 \%$ - 
$20 \%$ lower compressive strength values, compared to SCC without POFA. The 7-day flexural strengths have ranged from 5.12 to $6.19 \mathrm{MPa}$, whereas the 28-day flexural strengths have ranged from 5.46 to 6.90 MPa.

Also, the effect of BA and LS on Type 1 Portland cement content was studied by Sua-iam and Makul [23], for the development of SCC. Cement content of 550 $\mathrm{kg} / \mathrm{m}^{3}$ was maintained in all of the mixtures. In the research, the fine aggregate was replaced with $10,20,40,60,80$, or $100 \%$ BA and LS powder by volume. The incorporation of $20 \%$ of both BA and LS powder by volume effectively enhanced the workability and hardened properties of SCC. The results revealed that SCC mixtures containing LS and BA required lower water-cement ratios than SCC only containing BA, leading to higher flow ability.

The filling effect and the pozzolanic reactions of the POFA waste helped in improving the early age compressive strength. The optimal SCC, which contained a replacement of the fine aggregate with $20 \%$ of LS and $20 \%$ of BA, showed improved properties compared to normal SCC.

Kamal et al. [22] revealed that the addition of either steel fibre or polypropylene to SCC has altered the rheological and strength properties of SCC. The strength gained at 28 days increased with the use of steel fibres, compared to normal selfcompacting concrete without steel fibres. Research by Guneyisi et al. [19] assessed the use of nano silica and fly ash content, which was varied and assessed on both rheological and fresh properties of SCC. This was achieved by using four SCC series with a constant value for both the binder content and the water binder ratio. Interestingly, the results of the research showed that fly ash affected the fresh properties of SCC, while nano silica did not. This was as indicated in the increased time of the V-funnel and slump flow. Assessment of the torque and rotational speed was altered with the additives, using a rheometer. Moreover, both admixtures influenced both the slump value and the compressive strength.

Sua-iam and Makul [24] investigated the use of a high volume of lignite coal fly ash (FA), as a replacement for Type I Portland cement (OPC), and of rice husk ash (RHA) as a replacement for fine aggregate in the production of selfconsolidating concrete (SCC). This was achieved with the partial replacement of OPC with $0 \%, 20 \%, 40 \%$, and $60 \%$ of FA by volume, while fine aggregate was replaced with $0 \%, 25 \%, 50 \%, 75 \%$, and $100 \%$ of RHA by volume. According to the results, the replacement of RHA by weight of up to $25 \%$ yielded an appreciable compressive strength value. Also, Khaloo and Houseinian [20] proved that high strength could be attained by using $5 \%$ to $10 \%$ replacement of cement with silica fume, at both long and short term. Khayat et al. [30] worked on the fresh and hardened properties of concrete.

Additionally, an experimental investigation carried out by Bouzoubaa and Lachemi [31] revealed that, in an attempt to evaluate the performance of SCC with the addition of fly ash in high quantities, nine SCC mixtures have been used. The authors reported that, to come up with an economical SCC, high quantities of fly ash (class F) should be incorporated into the mix. However, up to $60 \%$ of FA could be used to produce SCC with a compressive strength of 40$50 \mathrm{MPa}$. 
Ray and Chattopadhyay [21] varied the percentage of silica fume by weight, using a $2 \%$ increment. The compressive strength was checked at different percentages. A positive relationship was recorded, which means that the higher is the percentage of silica fume, the higher are the workability and the compressive strength. Therefore, due to the abundance of pozzolanic characteristics, palm oil fuel ash is seen as a viable admixture in SCC production. SCC was produced by incorporation of palm oil fuel ash at 10, 15 and $20 \%$ by weight of Portland cement, and its mechanical and durability potential was evaluated under normal, acid and sulphate attack conditions. The early age results showed that class $\mathrm{C}$ fly ash had higher early strength and resistance to acid attack than class F. The long age compressive strength indicated that concrete containing fly ash showed little changes in the strength gained, but good rheology. LFA, a residue from lignite burnt in the power plant industry, was utilized in the production of selfconsolidating concrete. The comparative assessment showed that LFA had more free lime; sulphate and the cementitious material consisted of $75 \%$ of cement and $25 \%$ of fly ash. Vengala et al. [16] stated that an increase in the strength of SCC can be achieved by varying the paste volume between 0.43 and 0.45 . Meanwhile, Subramanian and Chattopadhyay [32] suggested that 0.9 and 1.1 are the suitable water to powder ratios for self-consolidation to be achieved. The essence of the research was to grossly reduce the shrinkage and improve the flexural strength properties of self-compacting concrete in paving work. The results showed that, at 28 days curing, concrete mixes with fly ash and blast furnace slags possess the same flexural strength properties, but the long age curing showed that the mix containing blast furnace slag had the highest beam strength. In its turn, shrinkage results showed that the concrete containing slag had the highest shrinkage value. Additionally, Hale et al. [33] carried out an experimental work on the replacement of cement with $25 \%$ blast furnace slag. The strength properties were assessed at 28 days of curing, and compared to normal cement and SCC. The results showed that the increase in the strength was $25 \%$ at 28 days of curing.

However, expansive additives usage in self-compacting and self-stressing concrete had a negative effect on the compressive strength (Carballosa et al. [34]). According to the authors, the compressive strength was reduced with the addition of expansive additives. It was also verified that self-stressing concrete with self-compacting characteristics could be designed by adopting the required cement super plasticizer, especially type K (calcium sulfo-aluminate). Three different brands of cement with two different mineral additives were introduced by the authors; the results showed that the addition of expansive additives to the SCC mix brought about bubbles in the mixture which, in turn, gave rise to a high slump value, while assessing the consistency in the fresh state. This has also affected the compressive strength of the sample, as it could be reduced due to the entrained air, which also led to the formation of micro cracks. However, the formation of amorphous calcium hydrated agglomerates was noticed with the type $\mathrm{G}$ additive (Carballosa et al. [34]). The use of both industrial waste and agricultural waste improved the rheology and strength properties of the SCC samples. The use of mineral additives in the form of metakaolin in concrete 
production was suggested by Patil et al. [8]. The material is derived from the dehydroxylation of kaolinitic clay.

\section{Effect of artificial aggregates on the strength and rheology of SCC}

Crushed limestone (LS) aggregate with different water to binder ratios was used by Uygunoglu et al. [35]. LS was replaced with MW (marble waste) or RA (recycled aggregate) in the ratio of $100 \%$. The rheological property was assessed using the slump-flow, the J-ring test, unit weight and air content. Additionally, the compressive strength, split-tensile strength, stress-strain relationship, modulus of elasticity and ultrasonic pulse velocity of the samples at the hardened states were assessed. The structural properties of the samples were compared at different curing days. The characteristic properties of the aggregate, such as the unit weight (or bulk density), shape and surface texture, to a large extent affected the rheological properties of the samples. Nonetheless, it was deduced that the reduction in the compressive strength value of the MW and RA samples was $31.5 \%$ and $7 \%$, compared to the LS samples with the highest water-binder ratio of 0.40 . Moreover, a replacement of LS with MW and RA showed a reduced modulus of elasticity, compared with that of SCC, due to lower strength. The authors have asserted that the required strength grade could be obtained by keeping the water-binder ratio low.

Tire Rubber Crumb (TRC) was used as a partial sand replacement (5\%, 10\%, and $15 \%$ ) material in the mix design of self-compacting concrete. Fine aggregates with fineness modulus of 2.9, specific gravity of $2.64\left(\mathrm{~g} / \mathrm{cm}^{3}\right)$, water absorption of $1.5 \%$, coarse aggregates with a maximum size of $12.7 \mathrm{~mm}$, specific gravity of $2.68\left(\mathrm{~g} / \mathrm{cm}^{3}\right)$ and water absorption of $0.8 \%$ were used in the research. According to the results of the study, the fresh concrete test showed that both fibre and TRC had negative effects on rheological properties of fresh concrete (Hesami et al. [25]).

TRC decreases the compressive strength, tensile strength, flexural strength, abrasive strength and modulus of elasticity, while it increases the water absorption of SCC. With the increase in rubber content, the compressive strength of concrete at the age of 28 days decreased, because aggregates are expected to bear the higher level of loads. The results of the tensile strength test indicated that the tensile strength decreased by adding more rubber to the sand replacement. Increasing the rubber content from 0 to $15 \%$, when no fibre was used, increased the water absorption by $26.47 \%$, while the addition of fibre decreased water absorption.

Sethy et al. [27] assessed the effect of using industrial slag as a partial replacement for cement. The effect was studied on the workability, selfcompatibility and strength of the concrete samples. The results showed that the strength value of 20 and $30 \mathrm{MPa}$ could be produced with a slag replacement of 80 to $90 \%$. On the other hand, the strength value of 60 to $100 \mathrm{MPa}$ could be achieved using $30 \%$ to $60 \%$ of industrial slag. Furthermore, a high volume of slag decreased the need for high retardation water reducing agent (HRWR). An inverse relationship was established for the slag replacement and the demand for HRWR. As the slag content increased from $30 \%$ to $90 \%$, the HRWR demand 
significantly decreased from $2.2 \%$ to $0.3 \%$. The measured plastic viscosities of SCC slag mixtures were in the range of 162.5 to $418.2 \mathrm{MPa}$, for slag replacements varying from $90 \%$ to $30 \%$. The compressive strength values revealed that it is possible to develop a wide spectrum of concrete from $20 \mathrm{MPa}$ to $100 \mathrm{MPa}$, by varying the replacements of slag between $90 \%$ and $30 \%$. Furthermore, ground granulated blast furnace slag (GGBFS) is an artificial aggregate derived from the production of iron. It was recycled and utilized as an artificial aggregate in the development of SCC. This was achieved using the cold bonding palletization process.

Cathode Ray Tube (CRT) glass waste cullet was blended with river sand, in proportions of 20 or $40 \%$ by weight, by Sua-iam and Makul [23]. To suppress potential viscosity effects, limestone powder was added at levels of 5, 10, or 15\% by weight. The utilization of CRT waste glass reduced the setting time, but increased the viscosity and fluidity of the developed concrete, according to Suaiam and Makul [23].

For powder type SCC mixes, commonly used in Belgium, a shear thickening (Herschel-Bulkley) flow behaviour of the fresh mixes is quite often observed Chauhan [36]. Three different concretes (normal vibrated concrete, selfcompacting concrete, and expansive SCC) for structural applications were studied, and the cylindrical strength was assessed with a target of $50 \mathrm{MPa}$. The presented results confirm many previous findings on normal vibrated concrete, in particular, regarding the influence of the L/D ratio and the failure mode (Muciaccia et al. [37]).

It is worthy to note that the deflection and cracking behaviour of the concrete structure depend on the flexural strength, which is an important criteria in pavement construction. Many factors have been shown to influence the flexural strength of concrete, particularly the level of stress, size, age and confinement to concrete flexure member, etc.

Research by Fathi and Farhang [38] showed an experimental insight into the effect of cyclic loading on both the compressive and flexural strength of one hundred and eight samples. The compressive strength was investigated, within the range of 25, 35 and $45 \mathrm{MPa}$. Research by Neville [39] assessed the strength of concrete using various mixes; the methodology involved the assessment of the splitting tensile strength at different curing ages. The effect of both short term and long term aging was also assessed.

According to Long et al. [40], mix proportioning parameters were designed, and its environmental impact by using sixteen SCC mixtures and different compositions of aggregates was assessed. This was done to quantitatively evaluate the corresponding environmental impacts of SCC by the use of the proposed index. The results of the analysis showed that the utilization of mineral admixtures reduced the e- $\mathrm{CO}_{2}$ and e-resource indices, but also decreased the eenergy index. The environmental impact index of SCC showed that increasing the quantum of mineral admixtures reduced the environmental impact index.

Additionally, adopting recycled limestone sand instead of river sand increases the e- $\mathrm{CO}_{2}$ index and e-energy index of SCC. The compressive strength results showed that e- $\mathrm{CO}_{2}$, e-energy, and e-resource indexes of SCC decreased when the 
compressive strength increased within a range of 30 to $60 \mathrm{MPa}$ (Long et al. [40]).

Subramanian and Chattopadhyay [32] worked on the design of a mathematical matrix for the strength of self-compacting concrete. This was achieved by varying some fine and coarse aggregates. The cement and water (paste) of binders was then filled into the voids of both coarse and fine aggregates, to ensure that the concrete in the fresh state would possess a good flow. Accordingly, Ravindrarajah et al. [41] investigated the cohesiveness of fresh concrete by increasing the quantity of fine materials in the mixtures. The results revealed that the mixtures had reduced segregation potential.

Furthermore, Persson [42] carried out an experimental investigation and numerical analysis on both the mechanical/strength properties of self-compacting concrete, by focusing on some parameters such as creep, shrinkage, etc. The methodology involved the postulation of eight different mixes varying the constituent elements, while the water-binder ratio was between 0.24 and 0.80 . Cristian [43] worked on the strength properties of self-compacting concrete in the hardened state. This was achieved by focusing on the split tensile and crushing strength. A comparative analysis was carried out on the strength properties of SCC and the conventional concrete. Moreover, the author also worked on the bonding properties of the coarse aggregate by using a Scanning Electron Microscope (SEM).

Dehn et al. [44] worked on the strength properties of SCC; the research focused on the strength properties of different mixes of SCC in the hardened state. In 2001, Ozyildirim [45] assessed the strength properties of three mix ratios for the design of SCC. The methodology involved the production of jointed plain concrete in paving work, which showed a promising potential based on the relevant road design codes.

\section{Discussion}

As suggested by Khayat [14], deformability and stability are crucial in ensuring a good SCC mix. Nagamoto and Ozawa [46] and Rodriguez [47] argued that workability is one of the key factors that should be considered while adopting supplementary materials in SCC production. This was also affirmed by Girish et al. [17], who stated that increasing the powder content ultimately improves rheology. Sustainability in the construction industry now brings the need to explore industrial and agricultural waste and minerals in the concrete production process, which is evidenced in SCC production. These additives are incorporated in an effort to reduce the cost of cement, as it is the most expensive component in concrete production. Additionally, with the advancement in technology, concrete is no longer seen as a composite of three elements (binder, aggregate, and water). From the various reviewed researches, the addition of some supplementary additives improved the strength properties of concrete.

Grdic et al. [18] asserted that fly ash and hydraulic lime proved to be adequate in improving the strength and workability of concrete, which was also stated by Menninger [48]. On the other hand, Guneyisi et al. [19] and Naik et al. [6] 
worked on class $\mathrm{F}$ and class $\mathrm{C}$ fly ash, which showed an improved compressive strength, likewise the following substances: silica fume (Khaloo and Houseinian [20]); polypropylene fiber (Ray and Chattopadhyay [21]); palm oil fuel ash (Ofuyatan et al. [49]); baggase ash (Sua-iam and Makul [23]); and metakaoline, microsillica and nanosillica (Barluenga et al. [28]).

It is recommended that future research focus on the addition of more than one type of agricultural waste to SCC production, as these wastes exhibit different pozzolanic properties. Furthermore, the use of a high volume of slag has decreased the need for High Retardation Water Reducing agent (HRWR). An inverse relationship was established for the slag replacement and the demand for HRWR. As the slag content increased from 30 to $90 \%$, the HRWR demand significantly decreased from $2.2 \%$ to $0.3 \%$.

Mix design of self-compacting concrete differs from normal concrete, due to the volume of both coarse and fine aggregates necessary to ascertain the required flow and workability. Ultimately, from the literature considered, it is imperative to state that reducing the coarse aggregate ratio, and increasing the paste volume with the use of viscosity modifying admixtures, raise the cost of SCC compared to normal concrete. Hence, the use of sustainable materials will lower the production cost. The use of agricultural waste such as palm oil fuel ash (POFA), BA, and so on, as supplementary materials, has altered SCC workability. Hence, the use of this waste in SCC calls for caution, as higher percentages have also reduced the strength properties, according to Ofuyatan et al. [49]. Interestingly, the durability properties have improved at a higher dosage. Bagasse ash addition alone does not improve the strength and workability of SCC, but its combination with limestone powder showed an improved strength. The utilization of the agricultural waste (Baggase and POFA) reduced the workability of SCC. Although the samples with a higher amount of POFA have revealed lower surface water absorption, the durability under acid attack was satisfactory compared to the samples with a lower content of POFA. Additional super plasticizer usage effect on fresh properties of the SCC's POFA was kept almost the same. The resistance of SCC against acid attack was attributed to the pozzolanic reaction of POFA conversion of calcium hydroxide $\mathrm{Ca}(\mathrm{OH})_{2}$ to the secondary $\mathrm{CeSeH}$ gel, leading to a denser concrete. To reduce the cost of cement in concrete production, the use of pozzolanas is considered an efficient and cost effective alternative.

Meanwhile, the use of industrial waste, according to Kamal et al. [22], Guneyisi et al. [19], Sua-iam and Makul [23], Khaloo and Houseinian [20] and Bouzoubaa and Lachemi [31], showed an improvement in the mechanical properties, compared to agricultural waste as supplementary material. Bouzoubaa and Lachemi [31] showed that the higher is FA content, the better is the strength of concrete, and the lower is its cost.

Furthermore, Ray and Chattopadhyay [21] asserted that the higher is the quantity of silica fume, the higher is the strength gained in SCC. Hale et al. [33] also stated that industrial waste accounted for SCC higher strength; the author's research showed that the use of slag led to a $25 \%$ increase in strength. Slag replacement around $80-90 \%$ improves SCC strength properties; however, it 
reduces HRWR volume. The use of marble waste and limestone as artificial aggregates revealed the first has improved SCC strength properties more than limestone, according to Uygunoglu et al. [35]. However, a negative effect was noticed on its rheology. On the other hand, Hesami et al. [25] showed that using TRC increases SCC water absorption. The use of expansive materials should be discouraged in SCC production, as Carballosa et al. [34] state that it has a negative effect on the strength properties of concrete. It can be concluded that industrial waste as a sustainable material in SCC production exhibits higher strength than the agricultural material. The use of industrial waste as a replacement for aggregates has further improved the strength properties of concrete. The considered literature has showed that there is no specific standard for the mix design of self-compacting concrete with varying constituent materials. SCC combines the properties of both high strength and high performance concrete and, therefore, will be effective in the construction of pavements that require a high axle load, such as BRT pavements. Therefore, there is a need to develop a mathematical relationship for the varied parameters used in a SCC mix proportion for pavement design purposes.

\section{Conclusion}

This review has assessed the use of supplementary materials in the concrete construction industry, with special focus on SCC. With the advancement in technology, concrete is no longer seen as a composite of three elements (binder, aggregate, and water). Fresh concrete properties and hardened concrete strength were studied using agricultural waste, industrial waste artificial aggregates and mineral additives. The results of the analysis showed that:

- with the advancement in technology, concrete is no longer seen as a composite of three elements (binder, aggregate, and water), as other supplementary materials are now being incorporated;

- the use of expansive materials should be discouraged in SCC production;

- to reduce the cost of cement in concrete production, its replacement with pozzolanas is considered as an efficient and cost effective practice;

- it can be concluded that industrial waste as a sustainable material in SCC production exhibits higher strength than agricultural material;

- the use of industrial waste as a replacement for aggregates further improved the strength properties of concrete;

- the use of marble waste and lime stone as an artificial aggregate revealed that the first improved SCC strength properties more than lime stone. However, a negative effect was noticed in its rheology;

- it could be inferred from this that the use of POFA may be adopted in SCC involving marine structures, as it showed higher resistance to chloride and sulphate attack;

- the addition of agricultural waste such as Bagasse ash alone does not improve the strength and workability of SCC, but its combination with lime stone powder showed an improved strength of concrete; 
- meanwhile, the use of industrial waste in concrete production showed an improvement in the mechanical properties, as against agricultural waste as supplementary material.

\section{Recommendation}

There exist gaps on the combination of more than one type of agricultural waste in SCC production. Future research should focus on the incorporation of more than one kind of agricultural waste, as they have different pozzolanic properties, and may exhibit complementary effects.

Additionally, most researches on SCC are centered on its suitability for structural purposes; it is recommended that future research should focus on its utilization in pavement construction.

Green construction and resource efficient materials are required in the concrete construction industry, in an effort to reduce the cost of cement, which is one of the most expensive constituents in concrete production.

\section{References}

1. Kurita M, Nomura T. High-flowable steel fiber-reinforced concrete containing fly ash. In: Malhotra VM, editor. Proceedings, 6th CANMET/ACI International conference on fly ash, silica fume, slag, and natural Pozzolans in concrete, SP- 178. Farmington Hills, MI: American Concrete Institute; 1998. p. 159-179.

2. Mohite SN. Applications of self-compacting concrete. 32nd conference on our world in concrete \& structures. Singapore; 2007.

3. Ouchi HO. Self-compacting concrete. J Adv Concrete Tech. 2013;1:5-15.

4. Okamura H, Ouchi M. Self-compacting concrete. J Adv Concrete Tech. 2013;1:5.

5. Naik TR, Kumar R, Ramme BW, et al. Development of high-strength, economical self-consolidating concrete. Construction Build Mater. 2012;463-469.

6. Naik TR, Ramme BW, Tews JH. Pavement construction with high-volume class C and F fly ash concrete. ACI Mater J. 1995;92:200-210.

7. Naik TR. Construction of Caisson foundations under water by tremie placement of concrete. Project Report to Wisconsin Power and Light. Madison: WI; 1974.

8. Patil SN, Gupta AK, Deshpande SS. Metakaolin- Pozzolanic Material for Cement in High Strength Concrete. IOSR J Mech Civil Eng. 2012; 46-49.

9. Aggarwal P, Siddique R, Aggarwal Y, et al. Self-Compacting Concrete Procedure for Mix Design. Leonardo Electronic J Pract Technol. 2008;12: $15-24$.

10. Ouchi M, Hibino M. Development, Applications, and Investigations of Selfcompacting Concrete. International Workshop. Kochi, Japan; 2000.

11. High-fluidity Concrete Construction Guideline. Japan Society of Civil Engineers: Concrete Library 93; 1999. 
12. Concrete: Technical Bulletin TB. An Introduction to Self-Consolidating Concrete (SCC). Grace Construction Products; 2005.

13. Aitcin PC. High performance concrete. London: E \& FN Spon; 1998.

14. Khayat KH. Workability, testing, and performance of self-consolidating Concrete. ACI Mater J. 1999;96:346-354.

15. Kennedy CT. The Design of Concrete Mixes. Proceedings of the American Concrete Institute. 1940.

16. Vengala J, Sudarsan MS, Ranganath RV. An experimental study for Obtaining self-compacting concrete. Ind Concrete J. 2008; 1261- 266.

17. Girish S, Ranganath RV, Vengala J. Influence of powder and paste on flow properties of SCC. Construction Build Mater. 2010;24:2481-2488.

18. Grdic Z, Despotovic I, Guneyisi EC, et al. Fresh and rheological behaviour of nano-silica and fly ash blended self-compacting concrete. Construction Build Mater. 2015;95:29-44.

19. Grdic Z, Despotovic I, Curcic GT. Properties of self-compacting concrete with different types of additives. Architecture Civil Eng. 2008;6:173-177.

20. Khaloo AR, Houseinian MR. Evaluation of properties of silica fume for use in concrete. Int Conference on Concretes. Dundee, Scotland; 1999.

21. Ray I, Chattopadhyay R. Effect of silica fume on superplasticizer concrete. Int Conference on Concretes. Dundee, Scotland; 1999.

22. Kamal MM, Safan MA, Etman ZA, et al. Mechanical properties of selfcompacted fibre concrete mixes. Housing and Building National Research Center; 2013.

23. Sua-iam G, Makul N. Use of increasing amounts of bagasse ash waste to Produce self-compacting concrete by adding limestone powder waste. J Cleaner Prod. 2013;57:308-319.

24. Sua-iam G, Makul N. Utilization of high volumes of unprocessed lignite-coal fly ash and rice husk ash in self-consolidating concrete. J Cleaner Prod. 2014;78:184-194.

25. Hesami S., Hikouei IS, Emadi SAA. Mechanical behaviour of selfcompacting concrete pavements incorporating recycled tire rubber crumb and reinforced with polypropylene fibre. J Cleaner Prod. 2016;133:228-234.

26. Ranjbar N, Behnia A, Alsubari B, et al. Durability and mechanical properties of self-compacting concrete incorporating palm oil fuel ash. J Cleaner Prod. 2016;112:723-730.

27. Sethy KP, Pasla D, Sahoo UC. Utilization of high volume of industrial slag in self-compacting Concrete. J Cleaner Prod. 2016;112:581-587.

28. Barluenga G, Puentes J, Palomar I. Early age monitoring of self Compacting concrete with mineral additions. Construction Build Mater. 2015;77: 66-73.

29. Sadek DM, El-Attar MM, Ali HA. Reusing of marble and granite powders in self-compacting concrete for sustainable development. J Cleaner Prod. 2016;121:19-32.

30. Khayat KH, Vachon M, Lanctot MC. Use of Blended Silica Fume Cement in Commercial Concrete Mixtures. ACI Materials J. 1997;183-192. 
31. Bouzoubaa N, Lachemi M. Self-compacting concrete incorporating high volumes of class F fly Preliminary ash results. Cement Concrete Res. 2001;31:413-420.

32. Subramanian S, Chattopadhyay D. Experiments for Mix Proportioning of Self Compacting Concrete. Ind Concrete J. 2002;13-20.

33. Hale WM, Bush TD, Russell BW. Interaction of blast furnace slag and Class C fly ash with type I cements. TRB. 2000;Paper No. 01-045.

34. Carballosa PL, García-Calvo JL, Revuelta D, et al. Influence of cement and expansive additive types in the performance of self-stressing and selfcompacting concretes for structural elements. Construction Build Mater. 2015;93:223-229.

35. Uygunoglu T, Topçu IB, Çelik AG. Use of waste marble and recycled aggregates in self-compacting concrete for environmental sustainability. J Cleaner Prod. 2014;691-700.

36. Chauhan H. Effect of Activated Flyash in Metakaolin based cement. National Conference on Recent Trends in Engineering \& Technology. Gujarat, India; 2011.

37. Muciaccia G, Giussani F, Rosati G, et al. Response of self-compacting concrete filled tubes under eccentric compression. J Constructional Steel Res. 2011;67:904-916.

38. Fathi H, Farhang K. Effect of cyclic loadings on heated self-compacting concrete. Construction Build Mater. 2014;69:26-31.

39. Neville A.M. Properties of concrete: fourth and final edition. England: Pearson Education Asia Pte Ltd; 2000.

40. Long G, Gao Y, Xie Y. Designing more sustainable and greener selfcompacting concrete. Construction Build Mater. 2015;84:301-306.

41. Ravindrarajah S, Siladyi D, Adamopoulos B. Development of High-Strength Self Compacting Concrete with reduced Segregation Potential. In: Wallevik O, Nielsson I, editors. International RILEM Symposium on Self-Compacting Concrete. RILEM Publ SARL; 2003.

42. Persson B. A comparison between mechanical properties of self-compacting concrete and the corresponding properties of normal concrete. Cement Concrete Res. 2001;31:193-198.

43. Cristian D. Tensile strength and bonding characteristics of self-compacting concrete. BSc (Mechanical Eng). Polytechnic University of Bucharest; 1995.

44. Dehn F, Holschemacher K, Weiße D. Self-compacting concrete (SCC) time development of the material properties and the bond behaviour, LACER. 2000;5.

45. Ozyildirim C. Evaluation of high-performance concrete pavement in Newport News, Virginia. TRB. Paper No. 01-3173; 2001.

46. Nagamoto N, Ozawa K. Mixture properties of Self-Compacting, HighPerformance Concrete. Proceedings of the 3rd CANMET/ACI Int Conferences on Design and Materials and Recent Advances in Concrete Technology, SP-172. American Concrete Institute: Farmington Hills; 1997. P. 623-637. 
47. Rodriguez J. Fast placement without vibration or mechanical consolidation Self-compacting concrete uses and applications. 2013. http://construction.about.com/od/Innovations/a/Self-CompactingConcrete.htm

48. Menninger R.C. (2006). How Should Strength be measured for Concrete Paving? NRMCA. TIL 420, and Data Summary. NRMCA TIL 451, NRMCA, Silver Spring, MD.Assessed on the 14th of January, 2016.

49. Ofuyatan T, Olutoge F, Olowofoyeku A. Durability Properties of Palm Oil Fuel Ash Self Compacting Concrete. Eng Technol Appl Sci Res. 2015;5:753756. 